IRSTI 52.47 .31

\title{
Removal of nickel and vanadium from crude oil by using solvent extraction and electrochemical process
}

\author{
A.N. Kurbanova, N.K. Akhmetov, A Yeshmuratov, R.N. Zulkharnay, \\ Y.T. Sugurbekov, G. Demeuova, M. Baisariyev and G.K. Sugurbekova* \\ PI "National Laboratory Astana", Nazarbayev University, \\ 53 Kabanbay Batyr ave., Astana, 010000, Kazakhstan \\ "e-mail: gulnar.sugurbekova@nu.edu.kz
}

\begin{abstract}
LLP Pavlodar Oil Chemistry Refinery crude oil contain high vanadium and nickel content, which contains more than $23.09 \mathrm{~g} / \mathrm{t}$ nickel and $58.59 \mathrm{~g} / \mathrm{t}$ vanadium. In this study we used two types of metal removing methods such as solvent extraction and electrochemical process. The present research is conducted for comparative analysis of the deasphalting with organic solvents and electrochemical method. Maximum efficiency of deasphalting, with cyclohexane as the solvent, in Soxhlet extractor was $66.4 \%$ for nickel and $51.2 \%$ for vanadium content from crude oil. Percentage of Ni extraction reached maximum of approximately $20 \%$ by using the electrochemical method in electrolysis cell, which was developed for this research. It consists of three sections: oil and protonating agent $(\mathrm{EtOH})$ solution between two conducting membranes which divides it from two capsules of $10 \%$ sulfuric acid and two graphite electrodes which cover all three parts in electrical circuit. Ions of metals' pass through membranes and remain in acid solutions. The best result was obtained in 60 minutes with ethanol to oil ratio of 1 to 3 respectively, current fits in to the range from $0.3 \mathrm{~A}$ to $0.4 \mathrm{~A}$, voltage changed from $12.8 \mathrm{~V}$ to $17.3 \mathrm{~V}$.
\end{abstract}

Key words: demetallization, deasphalting, electrochemical removal, heavy metals, petroleum engineering, solvent extraction

PACS number(s): 89.30 A; 89.30.aj; 82.45.Hk

\section{Introduction}

Most crude oils contain different metals with different concentrations ranging from a few million ppm to $1000 \mathrm{ppm}$, depending on origin of crude oil. Examples of such metals are $\mathrm{Na}, \mathrm{K}$, $\mathrm{Li}, \mathrm{Ca}, \mathrm{Sr}, \mathrm{Fe}, \mathrm{Cu}, \mathrm{Ag}, \mathrm{Mn}, \mathrm{Sn}, \mathrm{Pb}, \mathrm{Co}, \mathrm{Ti}, \mathrm{Au}$, $\mathrm{Cr}, \mathrm{V}$ and $\mathrm{Ni}$ [1]. From 10 to $60 \%$ of the total content of vanadium in crude oil forms steady porphyrin structures. (Figure1) [2]. These metals are usually combined with naphthenic acid in the form of surface active agents and in the form of complex organometallic compounds such as metalloporphyrins [3-4]. The concentration of metals depends on the origin of the petroleum. The presence of such metals in the processing of crude oil is undesirable, since they cause poisoning of catalysts, significantly deteriorate the properties of oil and petroleum products, increasing its corrosion activity [5]. The high content of $\mathrm{V}$ and $\mathrm{Ni}$ attracts attention for the production of metal oxides. These metals are undesirable due to its corrosion problems and catalyst contamination in cracking processes.

Demetallization of crude oil is the removal of oil distillation from the residual products and heavy oils of organometallic compounds with the extraction of metal impurities ( $\mathrm{V}, \mathrm{Ni}$, and also $\mathrm{Mg}, \mathrm{Fe}, \mathrm{Co}, \mathrm{Cu}$, etc.). Also demetallization usually results in the release of tar-asphaltene substances, partially sulfurand nitrogen-containing compounds. The most common methods of demetallization are deasphalting and hydrodemetallization [6-7].

Based on these data, the purpose of this article is to select, substantiate and validate the technology for removing unwanted metal impurities at the preliminary stage of oil refining without introducing changes to the main production line. 

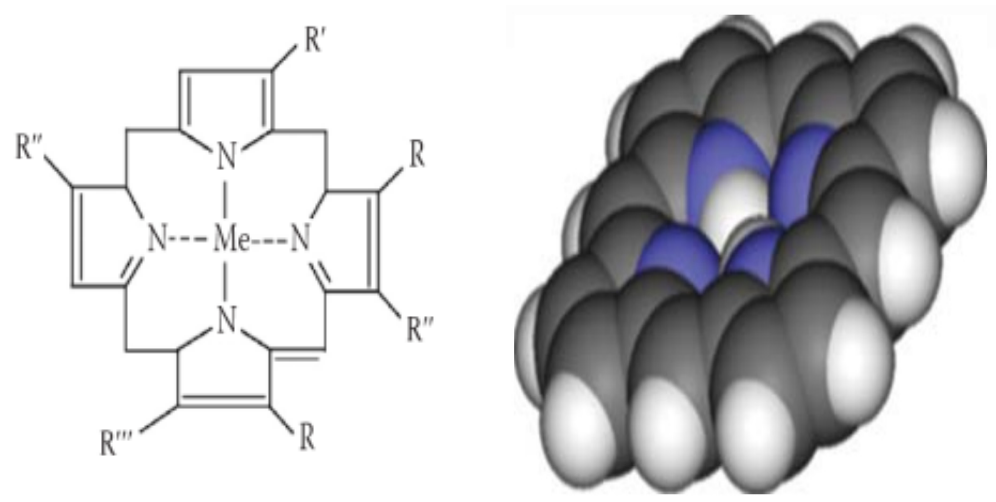

Figure 1 - Molecular structure of metalloporphyrin in oil

\section{Experimental}

In this research work Western Siberian crude oil processes from LLP 'Pavlodar Oil Chemistry Refinery' was experimentally examined by a solvent extraction method using three organically solvents to separate asphaltenes from crude oil and electrochemical method to recovery vanadium and nickel.

Table 1 - The main characteristics of the crude oils used

\begin{tabular}{|c|c|}
\hline The name of indicators & Actual value \\
\hline Density at $20^{\circ} \mathrm{C}, \mathrm{kg} / \mathrm{m}^{3}$ & 865.4 \\
\hline Water content, $\%$ wt. & traces $\left(0,03^{*}\right)$ \\
\hline Mass concentration of chloride salts, $\mathrm{mg} / \mathrm{dm}^{3}$ & 10.88 \\
\hline Sulfur content, $\%$ wt. & 1.51 \\
\hline Nickel content, $\mathrm{g} / \mathrm{t}$ & 23.09 \\
\hline Vanadium content, $\mathrm{g} / \mathrm{t}$ & 58.89 \\
\hline
\end{tabular}

${ }^{*}$ According to GOST $2477-65$, the water content is $0.03 \%$ by weight and less is taken for footprints (GOST - State Standard, Russian National Standard)

\subsection{Materials}

Materials were commercially obtained and used without further purification

Table 2 - Chemicals employed in this study

\begin{tabular}{|c|c|c|c|c|}
\hline Compound & Formula & CASRN $^{\text {a }}$ & Mass fraction purity $^{\text {b }}$ & Supplier \\
\hline Carbon tetrachloride & $\mathrm{CCl}_{4}$ & $56-23-5$ & 99.5 & Sigma -Aldrich \\
\hline Chloroform & $\mathrm{CHCl}_{3}$ & $67-66-3$ & 99.5 & Sigma - Aldrich \\
\hline Cyclohexane & $\mathrm{C}_{6} \mathrm{H}_{12}$ & $110-82-7$ & 99.5 & Sigma - Aldrich \\
\hline Sulfuric acid & $\mathrm{H}_{2} \mathrm{SO}_{4}$ & $7664-93-9$ & 98.0 & Sigma - Aldrich \\
\hline Ethanol & $\mathrm{C}_{2} \mathrm{H}_{5} \mathrm{OH}$ & - & 95.0 & $\begin{array}{c}\text { JSC 'Aydabulsky alcohol } \\
\text { factory' }\end{array}$ \\
\hline
\end{tabular}

${ }^{\text {a } C A S R N ~-~ C h e m i c a l ~ A b s t r a c t s ~ S e r v i c e s ~ R e g i s t r y ~ N u m b e r . ~}$

${ }^{\mathrm{b}}$ This is the purity of the material guaranteed by supplier; material was not further purified 


\subsection{Deasphalting of crude oil by extraction} method

The solvent extraction method of crude oil was obtained by using organic solvents such as carbon tetrachloride, chloroform, cyclohexane, as a solvent was performed using solvent to oil ratio 9:1 at the boiling temperature for each organic solvents for 1 hour surged with a consistent speed by an electromagnetic stirrer on the extractor Soxhlet (Figure2). Solvents are recovered by distillation for reuse in the deasphalting process.
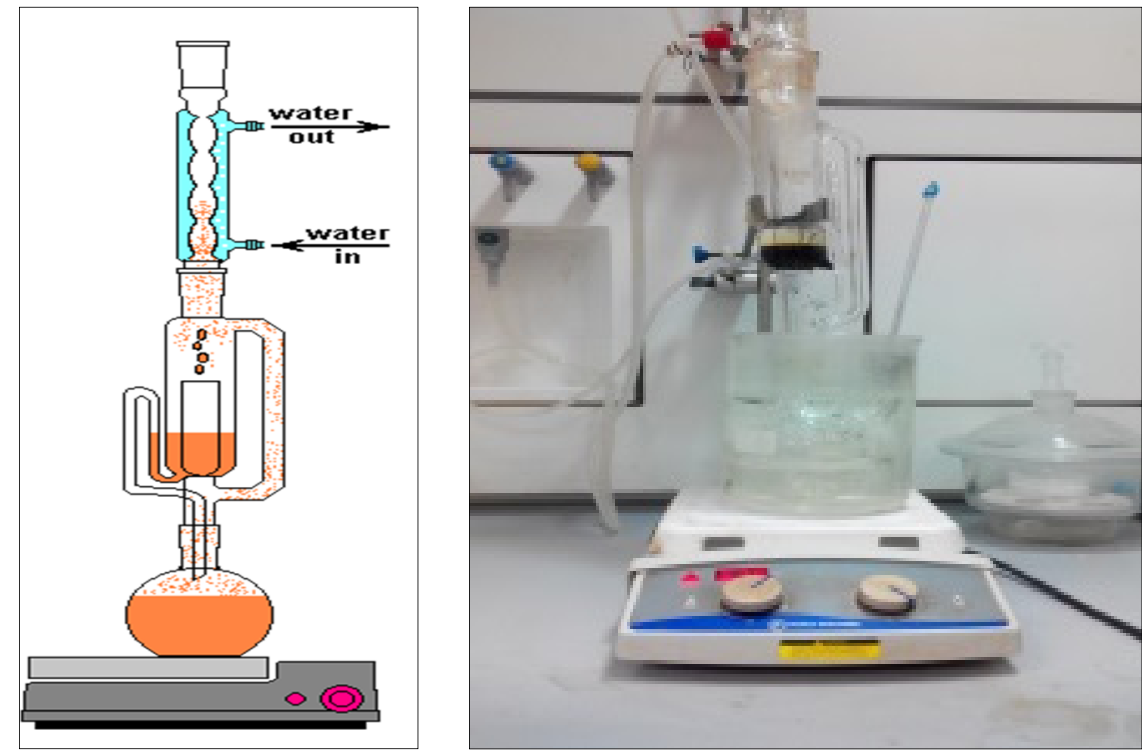

Figure 2 - Soxhlet apparatus for deasphalting of crude oil

\subsection{Electrochemical removing metals from} crude oil

Experimental work on the demetallization of crude oil by electrochemical extraction was carried out in an electrochemical cell (Figure3), which was designed specifically for this study and consists of three sections: crude oil with a protonating agent, in this case, ethanol between two conductive polypropylene membranes, which divides it into two capsules of $10 \%$ sulfuric acid as the electrolyte and two graphite electrodes that cover all three parts in the electrical circuit. Electric current is passed through a graphite electrode and metal ions pass through membranes and remain in acid solutions. Universal installation allows working with various current sources, potentiostats-galvanostats and other measuring equipment of electric current characteristics. Due to the small volume of the sample and the relatively large mass of the electrolyzer assembly and the large volume of electrolyte cells, it is possible to heat the process with a flexible thermo-bulb for flasks and glasse.

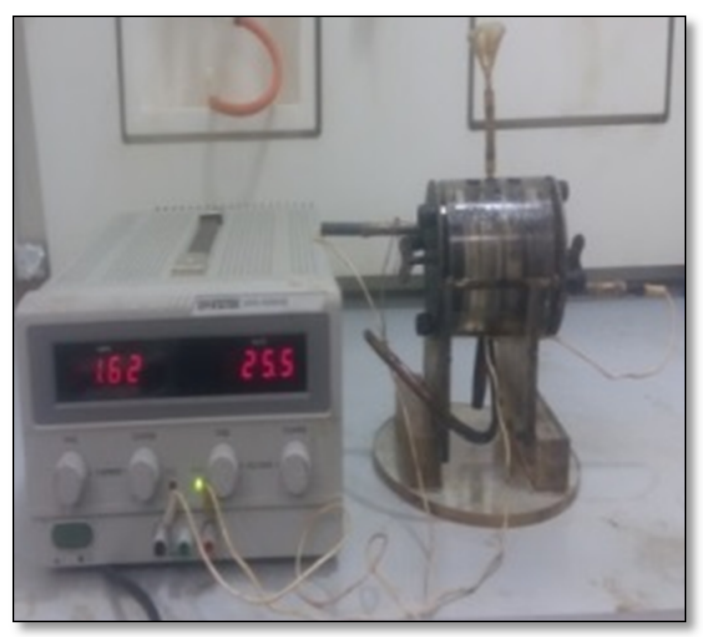

Figure 3 - Laboratory electrochemical cell for the electrolysis of crude oil

The yield of products in the deasphalting process of crude oil is linearly dependent on the physicochemical properties and electronic structure 
of n-alkanes used as a solvent. The formation of asphalt-resinous substances is associated with the electronic structure of the solvent. It is possible to regulate the yield and properties of the resulting concentrates of asphalt-resinous substances by changing the parameters of the solvent's electronic structure and its physicochemical properties, accordingly, deasphalts [9].

Table 3 - Results of ICP MS analysis after deasphalting

\begin{tabular}{|c|c|c|c|c|}
\hline \multirow{2}{*}{ Sample } & \multicolumn{2}{|c|}{ C, g/t } & \multicolumn{2}{c|}{ Percentage of extraction } \\
\cline { 2 - 5 } & $\mathbf{V}$ & $\mathbf{N i}$ & $\mathbf{V}$ & $\mathbf{N i}$ \\
\hline oil: $\mathrm{C}_{6} \mathrm{H}_{12}$ & 30,2 & 15,3 & $51,2 \%$ & $66,4 \%$ \\
\hline oil: $\mathrm{CHCI}_{3}$ & 14,4 & 7,8 & $24,4 \%$ & $33,8 \%$ \\
\hline oil: $\mathrm{CCI}_{4}$ & 8,4 & 4,5 & $14,2 \%$ & $19,5 \%$ \\
\hline
\end{tabular}

According to the tab III, as the tested organic deasphalts: cyclohexane, chloroform and carbon tetrachloride were used. The best deasphalting solvent was cyclohexane, which as a result of ICP MS extracts vanadium from crude oil to $51.2 \%$, nickel to $66.4 \%$.

Electrochemical recovery of metals from crude oil was carried out in a three-chamber cell in the presence of a protonating agent $(\mathrm{EtOH})$ and elemental analysis was studied by using CVA and ICP MS. The addition of a protonating agent led to an unstable change in the amperage from $5 \mathrm{~mA}$ to $30 \mathrm{~mA}$ during the electrolysis process (Figure3).

Alcohols are weak acids and feed protons onto strong bases to be forming alkoxides. The alkoxide ion is a strong conjugate base which indicates that the alcohols are a weak acid, but strong base and feed the electrons to hydrogen in a reaction with HX:

$$
\mathrm{PM}+\mathrm{HX} \leftrightarrow \mathrm{PH}+\mathrm{MX}
$$

Alcohols as one of the important organic synthetic reagents during the reaction, it can be protonated with mineral acids. The protonation of alcohol is the reaction of adding a proton to mineral acids, for example, ethanol:

$$
\mathrm{C}_{2} \mathrm{H}_{5} \mathrm{OH}+\mathrm{H}^{+} \rightarrow \mathrm{C}_{2} \mathrm{H}_{5} \mathrm{OH}_{2}^{+}
$$

As seen in (2), the last three atoms in the protonated structure, similar to molecules of water $\left(\mathrm{H}_{2} \mathrm{O}^{+}\right)$. Water has a fairly stable structure and it can be easily removed, leaving only carbocations. This scheme is called a "good leaving group".

The chemical concept of demetallization is based on the selective removal of metals from the organic part of the remaining oil with its minimal change. It is considered that many reactions of alcohols may act as the reactions of protonation and deprotonation. However, the separation of metals from oil is much more difficult, if they are found as bases, like alcoholates. Protonic alcohols are very active alkylating agents, if they contain $\beta \beta$ hydrogen. Alcohols represent the basis of Bronsted because of the presence of an unpaired electron over the oxygen atom, which makes them a proton acceptor. Alcohols with a C-O bond are significantly altered by protonation of hydroxyl groups. For example, protonated alcohols $\left(\mathrm{ROH}_{2}{ }^{+}\right)$ are easily subjected to substitution or elimination reactions through heterolysis of the $\mathrm{C}-\mathrm{O}$ bond.

Table III and Figure IV show the change of the current in the electrical circuit as a function of time with a ratio of oil to ethanol of 3 : 1 , a voltage $U=$ 25-30 V. The anode and cathode current intensities increase slightly with the course of the electrochemical process.

Table 4 - Kinetics of the change in the current strength of electrolysis at a voltage $U=25 \sim 30 \mathrm{~V}$ with ratio $1: 3$ oil and ethanol

\begin{tabular}{|l|c|c|c|c|c|c|}
\hline \multicolumn{1}{|c|}{ Time (min) } & $\mathbf{1 0}$ & $\mathbf{2 0}$ & $\mathbf{3 0}$ & $\mathbf{4 0}$ & $\mathbf{5 0}$ & $\mathbf{6 0}$ \\
\hline Current strength in the circuit (mA) & 11.8 & 13.2 & 12.6 & 14.1 & 16.5 & 19.2 \\
\hline Current in anode, I (mA) & 15.3 & 17.9 & 18.3 & 22.1 & 26.2 & 27.8 \\
\hline Current in cathode, I (mA) & 16.8 & 17.1 & 18.4 & 21.3 & 25.4 & 26.7 \\
\hline
\end{tabular}




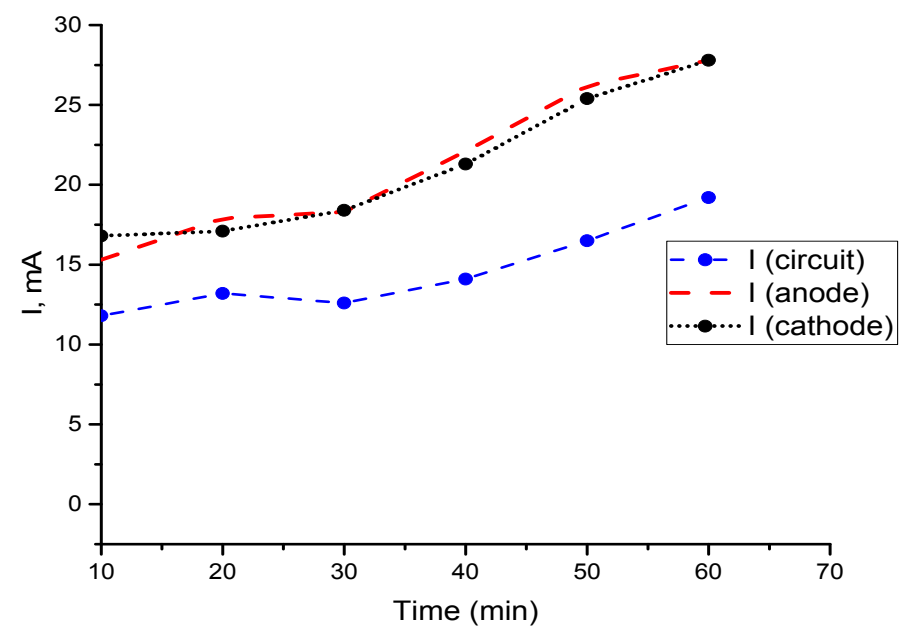

Figure 4 - Kinetics of the change in current strength as a function of the time of the electrolysis process

Table 5 and Figure 4 show the change in the current in the electrical circuit as a function of time at a ratio of oil to ethanol of 1: 3 , with a voltage $U=25-30 \mathrm{~V}$. Here, with an increase in the total current, the anodic and cathodic current intensities increase significantly with the time of the electrochemical process.

Table 5 - Percentage of extraction of nickel in the process of electrolysis

\begin{tabular}{|c|c|c|c|c|c|c|}
\hline Ratio/time & $\mathbf{1 0} \mathbf{~}$ in & $\mathbf{2 0} \mathbf{~}$ in & $\mathbf{3 0} \mathbf{~ m i n}$ & $\mathbf{4 0} \mathbf{~}$ in & $\mathbf{5 0} \mathbf{m i n}$ & $\mathbf{6 0} \mathbf{~ m i n}$ \\
\hline $3: 1$ & 19.64 & 3.61 & 3.24 & 4.95 & 4.77 & 2.88 \\
\hline $1: 1$ & 8.83 & 3.06 & 2.88 & 3.42 & 3.51 & 3.69 \\
\hline $1: 3$ & 4.32 & 3.78 & 4.68 & 5.59 & 6.76 & 5.41 \\
\hline
\end{tabular}

Table 6 - Percentage of extraction of vanadium in the process of electrolysis

\begin{tabular}{|c|c|c|c|c|c|c|}
\hline Ratio/time & $\mathbf{1 0} \mathbf{~ m i n}$ & $\mathbf{2 0} \mathbf{~ m i n}$ & $\mathbf{3 0} \mathbf{~ m i n}$ & $\mathbf{4 0} \mathbf{~ m i n}$ & $\mathbf{5 0} \mathbf{~ m i n}$ & $\mathbf{6 0} \mathbf{~ m i n}$ \\
\hline $3: 1$ & 1.34 & 0.88 & 1.27 & 2.26 & 2.33 & 1.77 \\
\hline $1: 1$ & 2.01 & 1.31 & 1.52 & 1.34 & 1.55 & 1.80 \\
\hline $1: 3$ & 1.66 & 1.13 & 1.83 & 1.80 & 2.47 & 2.11 \\
\hline
\end{tabular}

According to the results of calculating the degree of metal recovery, the optimal conditions for nickel were the ratio of ethanol to oil was $1: 3$, the deposition time was 10 minutes (tab. VI), and for vanadium were the ratio of ethanol to oil was 1:3, the deposition time was 50 minutes, (tab. VII), the degree of vanadium extraction was only $2.47 \%$, and the nickel was $19.64 \%$. From the obtained data, it can concluded that the maximum recovery for nickel is characteristic in the first 10 minutes of the experiment, vanadium is characterized by a not stable recovery dynamics, the first 10 minutes result is relatively significant, after which it begins to fall and then grow again. This fact may be due to unknown inverse processes, which are more characteristic of nickel.

Compared with the electrochemical method, the most promising method of extracting nickel and vanadium from oil is selective extraction with organic solvents. More often used are the release of metalloporphyrins from crude oil by alkanes, cycloalkanes, monohydric spirits. Extraction 
methods of deasphalting by liquid hydrocarbons are very effective and are used by refineries to remove metals from crude oil. In practice, the solvent deasphalting plant associated with the plant mixes the residual plant produced oil with a light hydrocarbon solvent in which the asphaltenes and most of the metals remain undissolved and removed from the product stream. The metal salts were removed from crude oil and fractions by extraction into an aqueous solution by demetallizing and demulsifying agents [10].

The methods are described above have been considered for use under the conditions of LLP Pavlodar Oil Chemistry Refinery and are difficult to use due to high capital costs for additional redistribution and/or high operating costs, or to the instability of the equipment used to the high corrosively of the reagents and products used in certain technologies. A clean and environmentally alternative can be processes of electrochemical removal of metals. Electrochemical processes have the advantage of using at atmospheric pressure and room temperature, thereby reducing overall production costs.

Table 7 - Results of analysis of cyclic voltammetric analysis after electrochemical deposition

\begin{tabular}{|l|c|}
\hline \multicolumn{1}{|c|}{ Sample } & Nickel weight $\mathbf{(} \boldsymbol{\mu g})$ in $\left.\mathbf{1 0 \%} \mathbf{H}_{\mathbf{2}} \mathbf{S O}_{\mathbf{4}} \mathbf{( 5 4} \mathbf{m l}\right)$ \\
\hline ratio $3: 1$ & 324 \\
\hline ratio $1: 1$ & 943 \\
\hline ratio $1: 3$ & 1413 \\
\hline
\end{tabular}

Based on the results of the studies, the metal content of vanadium and nickel in sulfuric acid by the ICP MS method was studied by transfer of metal ions to the electrolyte.

Table 8 - Results of extraction of nickel in the process of electrolysis. The concentration and mass of nickel in the initial sample of crude oil $\mathrm{C}(\mathrm{Ni})=23.09 \mathrm{~g} / \mathrm{t}$, the volume of crude oil in the cell $\mathrm{V}=3 \mathrm{ml}$, the volume of the electrolyte in the cell $\mathrm{V}=54 \mathrm{ml}$.

\begin{tabular}{|c|c|c|c|c|c|c|}
\hline Ratio/time & $\mathbf{1 0} \mathbf{~ m i n}$ & $\mathbf{2 0} \mathbf{~ m i n}$ & $\mathbf{3 0} \mathbf{~ m i n}$ & $\mathbf{4 0} \mathbf{~ m i n}$ & $\mathbf{5 0} \mathbf{~ m i n}$ & $\mathbf{6 0} \mathbf{~ m i n}$ \\
\hline $3: 1$ (ethanol:oil) & 19.64 & 3.61 & 3.24 & 4.95 & 4.77 & 2.88 \\
\hline 1:1 (ethanol:oil) & 8.83 & 3.06 & 2.88 & 3.42 & 3.51 & 3.69 \\
\hline 1:3 (ethanol:oil) & 4.32 & 3.78 & 4.68 & 5.59 & 6.76 & 5.41 \\
\hline
\end{tabular}

Table 9 - Results of extraction of vanadium in the process of electrolysis. The concentration and mass of nickel in the initial sample of crude oil $\mathrm{C}(\mathrm{V})=58.89 \mathrm{~g} / \mathrm{t}$, the volume of crude oil in the cell $\mathrm{V}=3 \mathrm{ml}$, the volume of the electrolyte in the cell $\mathrm{V}=54 \mathrm{ml}$.

\begin{tabular}{|c|c|c|c|c|c|c|}
\hline Ratio/time & $\mathbf{1 0} \mathbf{~} \mathbf{m}$ & $\mathbf{2 0} \mathbf{~}$ in & $\mathbf{3 0} \mathbf{~ m i n}$ & $\mathbf{4 0} \mathbf{~}$ in & $\mathbf{5 0} \mathbf{~ m i n}$ & $\mathbf{6 0} \mathbf{~ m i n}$ \\
\hline 3:1 (ethanol:oil) & 1.34 & 0.88 & 1.27 & 2.26 & 2.33 & 1.77 \\
\hline $1: 1$ (ethanol:oil) & 2.01 & 1.31 & 1.52 & 1.34 & 1.55 & 1.80 \\
\hline $1: 3$ (ethanol:oil) & 1.66 & 1.13 & 1.83 & 1.80 & 2.47 & 2.11 \\
\hline
\end{tabular}

\section{Conclusions}

As the investigated organic deasphalts cyclohexane, chloroform and carbon tetrachloride were used. The best deasphalting was cyclohexane $\left(\mathrm{C}_{6} \mathrm{H}_{12}\right)$, which as a result of ICP MS extracts vanadium from oil to $51.2 \%$, nickel to $66.4 \%$. Solvents for extraction were selected, the Soxhlet device was assembled for the deasphalting process, and deasphalting of crude oil was carried out by LLP Pavlodar Oil Chemistry Refinery as the primary stage of demetallization of crude oil.
Protonating agent in an electrochemical system can provide a cycle of reduction reactions, which releases the metal from the complex compounds, followed by electrolytic removal. The addition of ethyl alcohol as a protonating agent led to a change in the current strength from $5 \mathrm{~mA}$ to $35 \mathrm{~mA}$, indicating that the metal reduction process is in progress. The optimal conditions for nickel were calculated from the results of calculating the degree of metal recovery: the ratio of ethanol to oil was 1:3, the deposition time was 10 minutes, and for vanadium: the ratio of ethanol to oil was $1: 3$, the 
deposition time was 50 minutes, the vanadium recovery was only only $2.47 \%$, and nickel was $19.64 \%$.

The usage of the electrochemical method of demetallization is inexpedient without preliminary deasphalting. The electrochemical method of extracting metals from crude oil is economically unefficient, even with the use of a protonating agent, there was no detectable high metal recovery. Therefore, before the process of demetallization, it is required to conduct a process of deasphalting.

\section{Acknowledgements}

This work has been supported by the Ministry of Education and Science of Kazakhstan under the "Development of Methods for Demetallization of Crude Oil of LLP 'Pavlodar Petrochemical Plant' grant No. 0115PK02466.

\section{References}

1. C. Ovalles, et all. Degradacion oxidativa del crudo hamaca mediante ozonolisis // Fuel Processing Technology. 1996. - Vol. 48. - No.1-2, - P. 159-172.

2. K. Welter, et all. Electrochemical removal of metals from crude oil samples // Fuel Processing Technology. 2009. - Vol. 90. - P. 212-221. 89.

3. V. Valkovic. Trace elements in petroleum // Petroleum Publishing Company. - Oklahoma USA. - 1978. - P.86-

4. T.F. Yen, et all. The role of trace metals in petroleum // Ann Arbor Science Publishers, Ann Arbor, MI - 1975. Vol. 13. - P. 403-405.

5. V.A. Kalichevsky, et all // Chemical Refining of Petroleum, Reinhold Publishing Corp., New York, USA. 1942. - P. 45-311.

6. M. F. Ali, S. Abbas. A review of methods for the demetallization of residual fuel oils // Fuel Process. Tech. 2006. - Vol. 87. - P. 573-584.

7. J.Ancheyta, J.G. Speight. Hydroprocessing of heavy oils and residua // Chemical Industries., New York: CRC Press, 2007.Vol.180-P. 376

8. P. Anderson et all. Protonated alcohols are examples of complete charge-shift bonds // J. Org. Chem., - 2014. Vol.79. - No. 21. - P. 9998-10001.

9. Sh.M. Salem et all. Improving the quality of petroleum crude oils by deasphalting // Journal of Engineering Sciences. Assiut University. - 2011. - Vol. 39. - No. 4. - P. 885-896.

10. S. G. Acevedo et all. Reductive hydrogenation of asphaltenes and extraheavy oil residue with the alkaline metal sodium and potassium // Proc. 5th Unitar Int. Conf. on Heavy Crude Oil and Tar Sands. - 1991. - Vol.4. - P. 49-57.

11. C. Ovalles et all. Upgrading of Orinoco belt crude oil and its fractions by an eclectrochemical system in the presence of protonating agents // Fuel Processing Technology - 1996. - Vol. 48. - P.159.

12. S.Bankim et all. Simultaneous voltammetric determination of acetaminophen, aspirin and caffeine using an in situ surfactant-modified multiwalled carbon nanotube paste electrode // Electrochimica Acta. - 2010. Vol. 55, - No. 28, - P. 8638-8648.

13. Zh. Xu, et all. Demetalation-extraction of crude petroleum and fractions using fatty acids obtained by oxidation of paraffin waxes // Chinese patent No. CN 1431278. -2003.

14. S.V. Obrazcov. Method of demetallization and desulfurization of crude oil in the stream. Patent RF № 2,462,501. -2011 .

15. M. Greaney et all. Method for demetallizing refinery feed streams // US Patent No.5, 529,684. - 1996.

16. H. Shang et all. Microwave-assisted nickel and vanadium removal from crude oil // Fuel Processing Technology China. - 2016. - Vol. 142. - P. 250-257.

17. S.G. Kukes, et all. Chemical demetalation of heavy oils // Preprints American Chemical Society, Division of Petroleum Chemistry. - 1985. Vol. - No.30 (1). -P. 119-129.

18. S. Bankim et all. Simultaneous voltammetric determination of acetaminophen, aspirin and caffeine using an in situ surfactant-modified multiwalled carbon nanotube paste electrode // Electrochimica Acta. - 2010. - Vol. 55. - P. 8638-8648.

19. G.R. Dedeles et all. Microbial Demetallization of crude oil: Nickel porphyrin disodium as a model organometallic substrate // Biosci. Bioeng. - 2000. - Vol. 90. - No. 5. - P. 515-521.

20. R. G. Leliveld et all. How a 70-year-old catalytic refinery process is still ever dependent on innovation // Catalysis Today. - 2008. -Vol. 130. - P. 183-189.

21. J.M. Sugihara et all. Reductive desulfuration on vanadium and metalloporphyrin contents of fractions from boscan asphaltenes // Journal of Chemical and Engineering Data. - 1965. Vol. 10. - P. 190-194.

22. V. Valkovic. Trace elements in petroleum // Petroleum Publishing Company. - Tulsa OK. - 1978. - P. 40-100. 